https://helda.helsinki.fi

\title{
A prospective randomised study of dense Infinity cytological brush versus regularly used brush in pancreaticobiliary malignancy
}

\section{Kylänpää, Marja-Leena}

2016-05-03

Kylänpää , M-L , Boyd , S , Ristimaki , A, Lindstrom , O , Udd, M \& Halttunen , J 2016 , ' A prospective randomised study of dense Infinity cytological brush versus regularly used brush in pancreaticobiliary malignancy ', Scandinavian Journal of Gastroenterology , vol. 51 , no. 5 , pp. 590-593 . https://doi.org/10.3109/00365521.2015.1121514

http://hdl.handle.net/10138/223878

https://doi.org/10.3109/00365521.2015.1121514

publishedVersion

Downloaded from Helda, University of Helsinki institutional repository.

This is an electronic reprint of the original article.

This reprint may differ from the original in pagination and typographic detail.

Please cite the original version. 


\section{Scandinavian Journal of Gastroenterology}

\section{A prospective randomised study of dense Infinity cytological brush versus regularly used brush in pancreaticobiliary malignancy}

Leena Kylänpää, Sonja Boyd, Ari Ristimäki, Outi Lindström, Marianne Udd \& Jorma Halttunen

To cite this article: Leena Kylänpää, Sonja Boyd, Ari Ristimäki, Outi Lindström, Marianne Udd \& Jorma Halttunen (2016) A prospective randomised study of dense Infinity cytological brush versus regularly used brush in pancreaticobiliary malignancy, Scandinavian Journal of Gastroenterology, 51:5, 590-593, DOI: 10.3109/00365521.2015.1121514

To link to this article: http://dx.doi.org/10.3109/00365521.2015.1121514

Published online: 07 Dec 2015.

Submit your article to this journal $\pi$

Џ Article views: 42

Q View related articles $ᄃ$

View Crossmark data $\nearrow$ 


\title{
A prospective randomised study of dense Infinity cytological brush versus regularly used brush in pancreaticobiliary malignancy
}

\author{
Leena Kylänpääa ${ }^{a}$, Sonja Boyd ${ }^{b}$, Ari Ristimäki ${ }^{c}$, Outi Lindström ${ }^{a}$, Marianne Udd ${ }^{a}$ and Jorma Halttunen ${ }^{a}$ \\ ${ }^{a}$ Department of Gastrointestinal and General Surgery, Helsinki University Central Hospital, HUS Abdominal Center, Helsinki, Finland; \\ ${ }^{\mathrm{b}} \mathrm{HUSLAB}$, Helsinki University Hospital and University of Helsinki, Helsinki, Finland; 'Pathology, Research Programs Unit and HUSLAB, \\ University of Helsinki and Helsinki University Hospital, Helsinki, Finland
}

\begin{abstract}
Background and study aims Endoscopic retrograde cholangiopancreatography (ERCP) with a cytological sample is a valuable tool in the diagnosis of the aetiology of biliary stricture. Our aim was to evaluate whether a more dense Infinity ${ }^{\mathbb{R}}$ cytological brush is more sensitive in diagnosing malignancy than the regularly used brush. Patients and methods We recruited 60 patients with a biliary stricture suspicious for malignancy for a randomised controlled trial. Patients were randomly assigned to an Infinity ${ }^{\circledR}$ brush group $(n=30)$ and a regularly used cytology brush group $(n=30)$. All the patients had verified cancer during follow-up. Results Crossing the brush over the stricture was possible in each case without dilatation of the biliary duct. Brush cytology yield was good or excellent in $86.7 \%$ of cases with the Infinity ${ }^{\circledR}$ brush and $96.7 \%$ with the regular brush $(p=0.161)$. The cytological sample showed clear malignancy in three patients $(10.0 \%)$ in the Infinity ${ }^{\circledR}$ group and in $12(40.0 \%)$ patients of the regular brush group $(p=0.007)$. The cytological diagnosis was highly suspicious for malignancy or malignant in 14 patients (46.7\%) in the Infinity ${ }^{\circledR}$ group and in 23 patients $(76.7 \%)$ in the regular brush group $(p=0.017)$. The result was benign in 10 patients $(33.3 \%)$ in the Infinity ${ }^{\circledR}$ group and in four patients $(13.6 \%)$ in the regular brush group $(p=0.067)$. Conclusions With the standardised technique, the sensitivity of brush cytology is fairly good. The dense Infinity ${ }^{\circledR}$ brush does not show any advantage regarding sensitivity compared with the conventional cytology brush.
\end{abstract}

\section{ARTICLE HISTORY}

Received 24 September 2015

Revised 8 November 2015

Accepted 12 November 2015

Published online

4 December 2015

\section{KEYWORDS}

Biliary stricture; cytology; ERCP; sensitivity

\section{Introduction}

When biliary stricture causes jaundice, it is customary to perform endoscopic retrograde cholangiopancreatography (ERCP) and to take brush cytology before placing a biliary stent. In case of malignancy, operative treatment and/or neoadjuvant therapy is often considered. In either situation, the definitive diagnosis of malignancy is a necessity. Brush cytology has a considerable weakness regarding sensitivity. Earlier results of conventional brush cytology have been within the range of $20 \%$ to $50 \%$, mainly around $45 \%$ of sensitivity.[1-3] In a congress abstract, a relatively new Infinity ${ }^{\circledR}$ cytology brush had a promising sensitivity of $85 \%$ in detecting malignancy.[4] In another study, the Infinity ${ }^{\circledR}$ brush increased the cellularity of bile duct brushings compared with a standard brush.[5]

In the prospective randomised study, we aimed to find out if the use of a dense Infinity ${ }^{\circledR}$ brush could increase sensitivity in detecting pancreaticobiliary malignancy compared with a regular cytology brush.

\section{Patients and methods}

1281 and 1218 ERCPs were performed at Helsinki University Central Hospital in 2013 and 2014 respectively. From September 2013 to October 2014, 60 patients with suspected malignant pancreaticobiliary stenosis who underwent ERCP with brushing were recruited. During the same time period, 424 patients were treated endoscopically for biliary stricture. The patients were randomised to an Infinity ${ }^{\circledR}$ group (Infinity ${ }^{\circledR}$ brush, U.S. Endoscopy, $n=30$ ) and to a regular brush group (RX Cytology Brush, Boston Scientific, Natick, MA, $n=30$ ) (Table 1).

The indication for ERCP in each case was to get access beyond the stricture in the biliary duct to achieve a 
Table 1. Characteristics of the patients.

\begin{tabular}{llll}
\hline & Infinity $^{\circledR}(n=30)$ & Regular brush $(n=30)$ & $p$ Value \\
\hline Female/male $(n)$ & $22 / 8$ & $17 / 13$ & 0.18 \\
Age (years) & $66.5(54-90)$ & $68.0(54-86)$ & 0.42 \\
BMI & $24.5(17.7-46.1)$ & $24.6(16.0-35.5)$ & 0.42 \\
ASA $^{\text {a }}$ & $3(2-4)$ & $3(2-4)$ & 0.78 \\
US prior ERCP $(n)$ & 21 & 22 & 0.77 \\
CT prior ERCP $(n)$ & 30 & 30 & 1.00 \\
MRI prior ERCP $(n)$ & 4 & 8 & 0.20 \\
Stricture length $(\mathrm{cm})^{\text {a }}$ & $2(1-4)$ & $2(1-4)$ & 0.17 \\
Bilirubin (mg/L) prior ERCP & $182(31-384)$ & $224(4-501)$ & 0.26 \\
ALP (mg/L) prior ERCP & $367(183-2043)$ & $440(190-1157)$ & 0.87 \\
Pancreas cancer $(n)$ & 27 & 26 & 2 \\
Bile duct cancer $(n)$ & 2 & $2(1$ lymphoma, 1 gall bladder cancer) \\
Other $(n)$ & 1 (breast cancer metastasis) & $22.0(11-57)$ & 0.84 \\
Duration of ERCP (min) & $24.5(11-75)$ & $1(0-6)$ & 0.32 \\
Hospital stay after ERCP (days) & $1(0-6)$ &
\end{tabular}

${ }^{a}$ Figures are number of patients or median (range).

BMI: body mass index; ASA: American Society of Anaesthesiologists Physical Status Classification System; US: ultrasound; CT: computed tomography; MRI: magnetic resonance imaging; ALP: alkaline phosphatase.

cytology sample and to place a biliary stent. Exclusion criteria were patients aged below 18 years or, altered anatomy necessitating double-balloon ERCP. Following receipt of a signed informed consent, a sealed envelope was opened to determine group assignment. Patient characteristics are shown in Table 1. The Helsinki University ethical committee approved the study. ERCPs were performed by four experienced operators $(\mathrm{JH}, \mathrm{LK}, \mathrm{MU}, \mathrm{OL})$, who each undertake around 300 ERCPs a year. One patient from the regular brush group was excluded because of inadequate follow-up information and was replaced by the next suitable patient. Of the patients, 53\% were emergency cases. All patients received oral levofloxacillin $500 \mathrm{mg}$ as a prophylactic antibiotic a maximum of $1 \mathrm{~h}$ prior to ERCP unless they were already receiving other antibiotic treatment. Diclofenac suppositorium was given to $88.3 \%$ of patients. Seven patients did not receive diclofenac due to renal insufficiency $(n=5)$ or allergy $(n=2)$.

The primary tools for primary biliary cannulation were a sphincterotome (Ultratome ${ }^{\circledR}$, Boston Scientific, Miami, $\mathrm{FL}$ ) and a 0.035 -inch $260 \mathrm{~cm}$ long guide wire (Hydrosteer $^{\circledR}$, St. Jude Medical, Minnetonka, MN). If primary cannulation failed, further techniques (pancreatic sphincterotomy, needle knife precut) to gain access were used.

After gaining access to the biliary duct, the brush inside its sheath was passed above the stricture over the guidewire under fluoroscopic guidance. Leaving the bare brush above the stricture, the sheath was pulled back below the stricture. The brush was then withdrawn back into its sheath. This manoeuvre was repeated five times. The brush within its sheath was then pulled out as a single unit. The brush segment was cut from its wire and placed in $50 \%$ ethanol. Before that, $2 \mathrm{ml}$ of cytology solution was aspirated into a syringe. The sheath of the brush was then flushed with the cytology solution into the same sample. The whole sample, brush and flushing sample, was transported to the cytology laboratory for routine processing. Cytospin slides were stained with Papanicolaou stain. A cell block was also prepared if there was enough material, and cell block sections were stained with haematoxylin and eosin. Two experienced pathologists (A.R., S.B.) evaluated the samples first independently and then made a consensus statement being blinded to the brush used and to the underlying disease. Representativeness of the cytological sample was assessed by using three categories: 1, excellent (abundant cellularity with well-preserved cellular morphology); 2, adequate (moderate cellularity); and 3, poor (scant cellularity). No non-representative samples were obtained. Cytological diagnosis was divided into five categories: 1, normal (absence of atypical cells); 2, benign (abnormal but non-malignant); 3, low suspicion of malignancy; 4, high suspicion of malignancy; and 5, malignant.

Plasma total amylase or pancreas specific amylase were measured before and 4-6 $\mathrm{h}$ after ERCP. If the patient stayed in hospital overnight, plasma amylase was checked the following morning. If a complication occurred, the patient remained in hospital until recovered.

The final diagnosis of malignancy was based on histology (biopsy or surgical specimen) of the lesion or metastasis. With the absence of a histological sample, radiologically verified infiltration of adjacent organs or metastases during the follow-up was considered as verified malignancy.

The main focus of the study was to evaluate the sensitivity of the brush cytology sample to detect malignancy between the two groups. The second focus was to evaluate the sufficiency of the cytological 
sample. The frequency of complications, i.e., post-ERCP pancreatitis (PEP), cholangitis, bleeding, and perforation, was recorded. PEP was defined as elevated plasma amylase three times or more above the upper reference limit, and the presence of abdominal pain persisting for $24 \mathrm{~h}$ after the procedure. Cholangitis was defined as fever requiring intravenous or intramuscular antibiotics within $2 \mathrm{~d}$ of ERCP. Bleeding was defined as a need for repeat endoscopy due to melena or transfusion of blood within 1 week of ERCP. Perforation was diagnosed as an extravasation of contrast during ERCP or retroperitoneal air in computed tomography following the procedure. The severity of the complications was defined according to consensus criteria.[6]

\section{Statistical analysis}

Sample size determination was carried out as follows: power $=0.8 ; \alpha=0.05$; In previously reported non-randomised results, the sensitivity of the regular cytology brush was $45 \%$ compared with a figure of $85 \%$ for the Infinity ${ }^{\circledR}$ brush [4] in detection of pancreaticobiliary malignancy, resulting in a sample size of 60 patients $(30+30)$. Data are presented in the form of median (range) or number of patients and percentages. The data were analysed using SPSS v 22.0 (IBM Corporation, Somers, NY). The chi-square test was used to test for differences between categorical variables. A nonparametric Wilcoxon-Mann-Whitney test was used to compare differences in continuous and ordinal variables. Probabilities below 0.05 were regarded as statistically significant.

\section{Results}

The final diagnosis of all patients was malignant, 88.3\% being pancreatic cancers (Table 1). Malignancy was confirmed from surgical specimen $(n=22)$ or by another histopathological sample from the tumour or metastasis $(n=14)$. In the rest of the patients $(n=24)$, malignancy was verified with radiology. The length of the follow-up of these 24 patients was median 11 months (2-22). The representativeness of brush cytology samples was adequate or excellent at $86.7 \%$ with the Infinity ${ }^{\circledR}$ brush and $96.7 \%$ with the regular brush $(p=0.161)$. The brush sample showed clear malignancy (category 5) in 3 patients (10.0\%) in the Infinity ${ }^{\circledR}$ group and in $12(40.0 \%)$ in the regular brush group ( $p=0.007$, Table 2$)$. The result was highly suspicious for malignancy or malignant in 14 patients (46.7\%) in Infinity ${ }^{\circledR}$ group and in 23 patients (76.7\%) in regular brush group $(p=0.017)$. Each patient with the result of clear malignancy (category 5) or high suspicion of malignancy (category 4) had cancer
Table 2. Cytological findings in infinity ${ }^{\circledR}$ group and regular brush group.

\begin{tabular}{lcc} 
Cytological category & Infinity $^{\circledR}(n=30)$ & Regular brush $(n=30)$ \\
\hline 1 & 6 & 2 \\
2 & 4 & 2 \\
3 & 6 & 3 \\
4 & 11 & 11 \\
5 & 3 & 12 \\
\hline
\end{tabular}

resulting in $100 \%$ specificity. The brush cytology result was benign (category 1 or 2 ) in 10 patients (33.3\%) in the Infinity ${ }^{\circledR}$ group and in four patients $(13.3 \%)$ in the regular brush group $(p=0.129)$. In four cases of bile duct cancer, brush cytology was considered as having low suspicion of malignancy (category $3, n=1$ ) or high suspicion of malignancy (category $4, n=3$ ). When cytologically malignant cases were compared with the rest of the patients, there were no significant differences in age $(p=0.891)$, pre-ERCP bilirubin value $(p=0.253)$ or the length of the biliary stricture $(p=0.068)$. Neither was there any difference in the similar parameters when clear malignancy and high suspicion of malignancy were compared with the rest $(p=0.732, p=0.305, p=0.546$, respectively).

PEP was diagnosed in two patients (3.3\%), one in each study group. Both PEP cases were treated conservatively. The first PEP patient (Infinity ${ }^{\circledR}$ group) stayed in hospital for $6 \mathrm{~d}$ and is considered thus as moderate. The other PEP patient was discharged $3 \mathrm{~d}$ after ERCP having mild disease. Post-sphincterotomy bleeding occurred in one patient (1.0\%) and was treated endoscopically. One patient had guide-wire perforation but recovered uneventfully and was discharged from hospital the following day after ERCP. Hyperamylaesaemia without clinical signs of PEP was present in none in the Infinity ${ }^{\circledR}$ group and in 8 in the regular brush group $(p=0.002)$. There were no cases of cholangitis nor perforation, nor were there any deaths within $30 \mathrm{~d}$ of ERCP. There were 17 deaths (28.3\%) during the follow-up.

\section{Discussion}

The sensitivity of the regular brush was surprisingly good. One reason for that is most probably the policy to cut the whole brush into the sample and to flush the catheter to achieve adequate cellular yield. Another reason might be the patient selection since each patient had high suspicion of pancreaticobiliary malignancy. Anyhow, the result of the present study favours the use of the regular brush since the price of the Infinity ${ }^{\circledR}$ brush is considerably higher. 
There are studies showing that brush cytology is more sensitive in biliary duct cancer than in pancreatic cancer. In the present study, we only had four patients with biliary duct cancer and none of them showed clear malignancy in brush cytology. However, the present study was underpowered to draw any conclusions in differences in various malignancies causing biliary stricture.

Most patients with malignancy causing biliary stricture require ERCP with stenting. In ERCP, brush cytology is usually taken without increasing the rate of procedure related complications. The fact that there were statistically significantly more hyperamylaesemia cases in the regular brush group than in the Infinity ${ }^{\circledR}$ group in the present study is most probably coincidence and anyhow without clinical significance. If the definite diagnosis was possible to gain by ERCP and brush cytology, the decision when planning the appropriate therapy for the patients would be easier and would avoid the need for additional expensive invasive procedures for tumour tissue sample collection, such as endoscopic ultrasoundguided biopsy or cholangioscopy-assisted biopsy.

There are studies that show that advanced age [7] and a high bilirubin level are associated with increased sensitivity for detecting malignancy with brush cytology.[2] However, in the present study we could not find any relation between the accuracy of brush cytology and age, bilirubin level or even length of the stricture.

One shortcoming in this study was that the patients were not consecutive. We tried to avoid recruiting elderly patients in poor condition because the probability of having a definitive diagnosis of malignancy would have been obvious. In that way, only one recruited patient needed to be replaced by another.

\section{Conclusions}

The sensitivity of brush cytology to detect pancreaticobiliary malignancy is fairly good, when the brush is cut into the sample. The dense Infinity ${ }^{\circledR}$ brush is not superior regarding sensitivity compared with the regular cytology brush.

\section{Disclosure statement}

Drs Kylänpää Leena and Halttunen Jorma received a research Grant from UpViser OY.

\section{References}

[1] Kocjan G, Smith A. Bile duct brushings cytology: potential pitfalls in diagnosis. Diagn Cytopathol. 1997;16:358-363.

[2] Parsi M, Deepinder F, Lopez R, et al. Factors affecting the yield of brush cytology for the diagnosis of pancreatic and biliary cancers. Pancreas. 2011;40:52-54.

[3] Alizadeh M, Mousavi M, Salehi B, et al. Biliary brush cytology in the assessment of biliary strictures at a tertiary center in Iran. Asian Pac J Cancer Prev. 2011;12:2793-2796.

[4] Barrioz T, Wangermez M, Levillain P, et al. La brosse Infinity ${ }^{\circledR}$ améliore les resultants du brossage cytologique des sténoses biliaires malignes. Endoscopy. 2013;45: A7407.

[5] Shieh F, Luong-Player A, Khara H, et al. Improved endoscopic retrograde cholangiopancreatography brush increases diagnostic yield of malignan biliary strictures. World J Gastrointest Endosc. 2014;6:312-317.

[6] Cotton P, Lehman G, Vennes J, et al. Endoscopic sphincterotomy complications and their management: an attempt at consensus. Gastrointest Endosc. 1991;37:383-393.

[7] Mahmoudi N, Enns R, Amar J, et al. Biliary brush cytology: factors associated with positive yields on biliary brush cytology. World J Gastroenterol. 2008;28:569-573. 